\title{
Drawing of Low-Molecular-Weight Polyethylene Gel Films and Ultrahigh-Molecular-Weight Polyethylene Melt Films
}

\author{
Tetsuya Ogita, Hirotsugu Yasuda, Nobuyasu Suzuki, \\ Masatomo Minagawa, and Masaru Matsuo*, ${ }^{\dagger}$ \\ Department of Materials Science and Engineering, Faculty of Engineering, \\ Yamagata University, Yonezawa 992, Japan \\ * Department of Clothing Science, Faculty of Home Economics, \\ Nara Women's University, Nara 630, Japan
}

(Received June 10, 1992)

\begin{abstract}
Gel films of low-molecular-weight polyethylene (LMWPE) were prepared by partial melt under compression. The gel films could be readily stretched up to 20 times at $135^{\circ} \mathrm{C}$. The Young's modulus is in the range $32-34 \mathrm{GPa}$. This value is slightly higher than that of melt-crystallized ultrahigh-molecular-weight polyethylene (UHMWPE) drawn to 40 times at the same temperature but is much lower than that ( $>200 \mathrm{GPa}$ ) of UHMWPE gel films drawn to 300 . This behavior is discussed in terms of the morphology of the gel film as studied by wide-angle $\mathrm{X}$-ray diffraction, small-angle $\mathrm{X}$-ray scattering, and birefringence measurements. It turns out that the Young's modulus, 32-34 GPa, of the LMWPE gel film is attributed to a suitable degree of chain entanglement to assure effective transmission of the drawing force associated with a significant crystal transformation from a folded to a fibrous type. In spite of the perfect orientation of the $c$-axes, however, the Young's modulus of the LMWPE gel film is much lower than that of the UHMWPE gel films with a draw ratio of 300. This is thought to be due to low crystallinity and short length of extended crystal chains.
\end{abstract}

KEY WORDS Low-Molecular-Weight Polyethylene / Gel Films / Partial Melt / Compression / Ultrahigh-Molecular-Weight Polyethylene /

In a previous work, ${ }^{1}$ the morphology of polyethylene gels was investigated in relation to molecular-weight dependence. Low-molecular-weight polyethylene (LMWPE), the viscosity-average molecular weight, $\bar{M}_{v}$, being less than $3 \times 10^{5}$, and ultrahigh-molecularweight polyethylene (UHMWPE) $\left(\bar{M}_{v}=1 \times\right.$ $10^{6}$ and $3 \times 10^{6}$ ) were used as test specimens. The gels of LMWPE were found to have no ability to form a film on drying; instead they broke up into flakes. They were composed of two-dimensional spherulites stacked on top of one another to form periodic structures parallel to the plane of the dry gel. This indicates that there should be no entanglement in the crystal mats because the surface of the

+ To whom all correspondence should be addressed. crystal would contain only regular folded chain loops. In contrast, a gel of UHMWPE could form a film and it was composed of rodlike textures oriented parallel to the plane of the dry gel film. Within the rod, large crystal lamellae like single-crystal mats were highly oriented with their flat faces parallel to the rod surfaces. These results point out an essential problem in relief as to why UHMWPE have a required condition for preparing high-strength and high-modulus polyethylene fibers through elongation up to consistently high draw ratio. To analyze this problem, the crystallinities of LMWPE gels were measured. The values were beyond $80 \%$. These values were almost equal to the values 
of UHMWPE gels and were higher than those of LMWPE melt films. ${ }^{1}$ This was attributed to the relatively short chain length available for the formation of the amorphous phase per molecule; as a result, there was an insufficient level of chain entanglements to form films.

It should be emphasized that LMWPE fibers and films are very important in a commercial base. This is due to the fact that the production rate of high-modulus fibers from UHMWPE gels is far less than commercially interesting speed because of a drastic increase in viscosity with increasing concentration of solution. From this viewpoint, this paper deals with the drawing mechanism of LMWPE dried gel film prepared by partial melt, in terms of morphological aspects by using wide-angle X-ray diffraction (WAXD), small-angle X-ray scattering (SAXS), and birefringence measurements.

\section{EXPERIMENTAL}

Films of LMWPE gel were prepared by using Sholex Super $5551 \mathrm{H}\left(\bar{M}_{v}=3 \times 10^{5}\right)$ according to the method in the previous paper. ${ }^{1}$ The LMWPE gels could not form films on drying because of its high crystallinity $(>80 \%)$; instead they broke up into flakes. The resultant gels were sandwiched between Teflon sheets and pressed at $20 \mathrm{MPa}$ at the desired temperatures, 80,100 , and $120^{\circ} \mathrm{C}$ for $30 \mathrm{~min}$. They were quenched in a ice-water bath. Through this process, the gels formed a film. This is thought to be due to increase in the number of entanglement meshes brought about by partial melting. On the other hand, two kinds of UHMWPE powders, Hizex Million $145 \mathrm{M}, \bar{M}_{v}=1 \times 10^{6}$ and Hizex Million $240 \mathrm{M}, \bar{M}_{v}=3 \times 10^{6}$, were sandwiched between Teflon sheets at $220^{\circ} \mathrm{C}$ for $30 \mathrm{~min}$ under a pressure of $5 \mathrm{MPa}$. The molten sample was cooled to room temperature slowly under a pressure of $0.5 \mathrm{MPa}$. The thickness of the resultant films was in the range of $100-300 \mu \mathrm{m}$. The films were cut into strips of length $30 \mathrm{~mm}$ and width $5 \mathrm{~mm}$. Using the same method, LMWPE (Sholex Super 5551H) melt films were also prepared to discuss the drawability in comparison with the gel films prepared by the annealing. Every specimen was put into a hot oven at a desired temperature under nitrogen and elongated manually without annealing process. On drawing of the LMWPE gel film, annealing was omitted to avoid morphological change of specimens, since the SAXS patterns showed a drastic change by annealing at temperature $>120^{\circ} \mathrm{C}$. In doing so, $135^{\circ} \mathrm{C}$ was the most suitable temperature to assure their maximum draw ratio of 20 for the LMWPE gel films. Draw ratios were determined in the usual way by measuring the displacement of ink marks placed on the specimen prior to drawing.

UHMWPE melt films were prepared by the same method as the LMWPE melt film preparation discussed above.

Measurements of density, melting point, and birefringence are described elsewhere in detail. $^{1,2}$ The X-ray measurements were carried out by $12 \mathrm{~kW}$ rotating anode $\mathrm{X}$-ray generator (RDA-rA), which were also described elsewhere in detail. ${ }^{1,2}$

\section{RESULTS AND DISCUSSION}

Table I lists changes in crystallinity of the original LMWPE gel (no-heat treatment) and gel films as a function of annealing temperature. Each gel film was prepared; each half-dried gel was sandwiched between Teflon

Table I. Change in crystallinity of gels as a function of annealing temperature under compression of $20 \mathrm{MPa}$

\begin{tabular}{cc}
\hline Annealing temperature & Crystallinity $/ \%$ \\
\hline $\begin{array}{c}\text { Original } \\
\text { (no-heat treatment) }\end{array}$ & 82.5 \\
$80^{\circ} \mathrm{C}$ & 82.0 \\
$100^{\circ} \mathrm{C}$ & 81.0 \\
$120^{\circ} \mathrm{C}$ & 80.0 \\
\hline
\end{tabular}


sheets during the evaporation of solvent and was heat-treated at the indicated temperatures under a compression of $20 \mathrm{MPa}$. The dried gels formed a film. With increasing annealing temperature, crystallinity becomes lower by partial melting of crystallites. Repeated measurements provided values within experimental error less than $3 \%$. Judging from the formation of film, the annealing temperature provided active mobility of the original amorphous segments and new amorphous segments arose by the partial melting of small size crystallites. These amorphous chain segments are thought to consist of interpenetrating random coils which form intra- and intermolecular coupling entanglements.

Figure 1 presents the change in the profile of the differential scanning calorimetry (DSC) curves of the gel films prepared by annealing at the indicated temperatures. With increasing annealing temperature, the profile of peak becomes sharper and melting point becomes slightly higher. This implies that during annealing, the small size crystallites were melted and the big size crystallites were maintained. This concept is in good agreement with the decrease in crystallinity by annealing under compression listed in Table I.

Figure 2 shows WAXD (A) and SAXS (B) patterns (end view) of the annealed gel films. In making $\mathrm{X}$-ray diffraction measurements, great care was taken for dried gels because of brittle structure-like single-crystal mats.

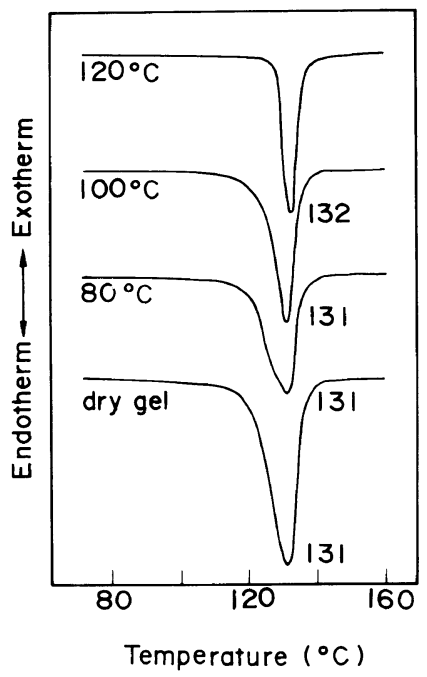

Figure 1. DSC curves of dry gel and gel films prepared by heating at the indicated temperatures under compression of $20 \mathrm{MPa}$.
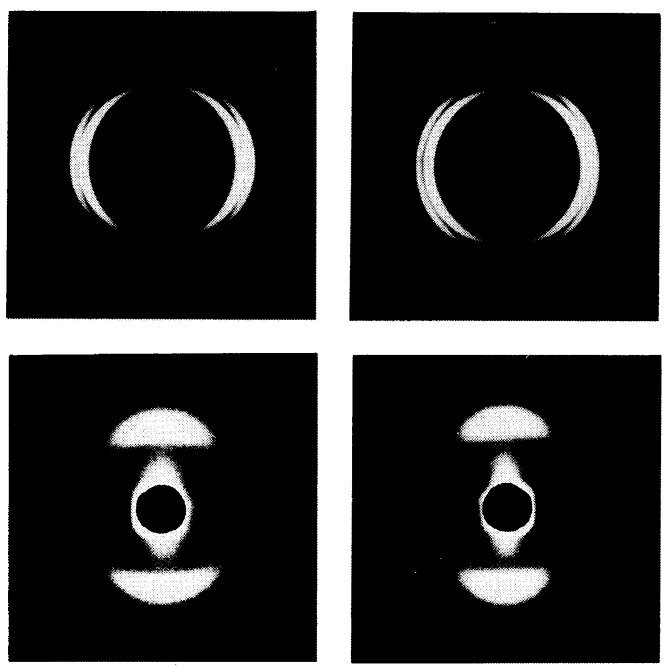

\section{Dried Gel}
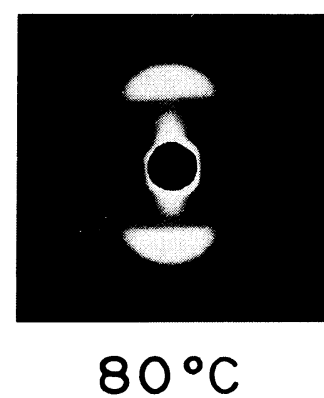
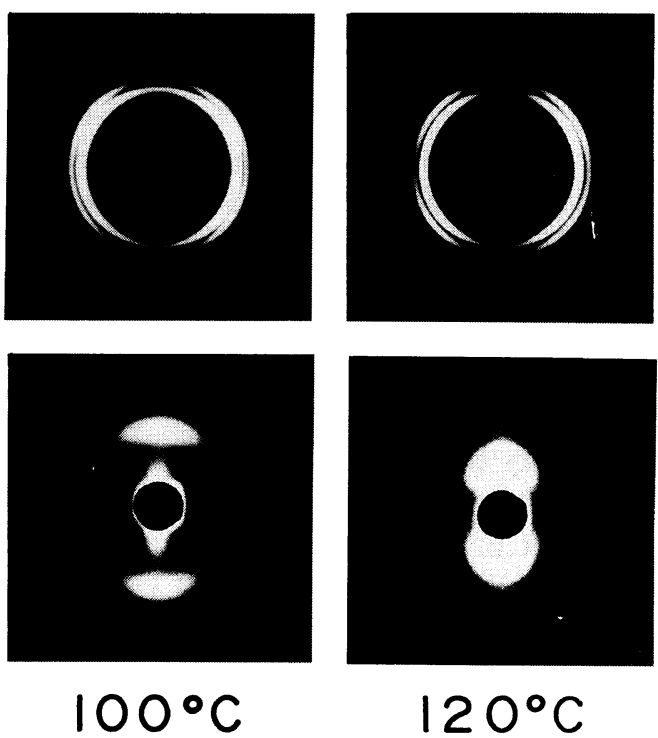

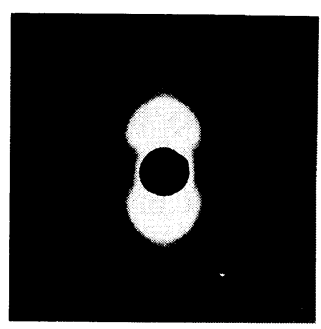

$120^{\circ} \mathrm{C}$

Figure 2. WAXD (A) and SAXS (B) patterns of dry gel and gel films prepared by heating at the indicated temperatures under compression of $20 \mathrm{MPa}$. 
Table II. Long period of dry gel and gel films prepared by annealing at the indicated temperatures under compression of $20 \mathrm{GPa}$

\begin{tabular}{cc}
\hline Annealing temperature & Long period $/ \AA$ \\
\hline Dry gel & 116 \\
$80^{\circ} \mathrm{C}$ & 113 \\
$100^{\circ} \mathrm{C}$ & 119 \\
$120^{\circ} \mathrm{C}$ & 192
\end{tabular}

The WAXD pattern indicates the preferential orientation of the $c$-axes perpendicular to the film surface. When dried gels were pressed at the indicated temperature, the diffraction arcs of the $(200)$ plane showed the scattering maxima indicating a characteristic orientation of the $a$-axes. That is, the $a$-axes are tilted at $40^{\circ}$ with respect to the film normal direction. The SAXS patterns of the specimens annealed at temperature $\leqq 100^{\circ} \mathrm{C}$ show distinct scattering maxima in the meridional direction. This indicates that as in the case of dried gels the annealed gel films are composed of crystal lamellae highly oriented with their large flat faces parallel to the film surface. At annealing temperature of $120^{\circ} \mathrm{C}$, the scattering maxima become indistinct, since the maxima more close to the center of the pattern considerably. This indicates a drastic increase in folding period (long spacing) at $120^{\circ} \mathrm{C}$ and this result is shown in Table II. Such behavior is similar to the annealing effect of single-crystal mats. ${ }^{3}$

Table III shows changes in crystallinity and melting points of heat-treated samples as a function of draw ratio $\lambda$. The maximum draw ratio increased by a factor of 20 , which was higher than that $(\lambda=10-12)$ of the melt films. It may be expected that in comparison with the melt film, the gel film prepared by partial melt involves more suitable entanglements that act as intermolecular crosslinks and effectively transmit the drawing force. The crystallinity increases slightly with draw ratio but the degree is almost independent of the annealing temperature. A slight increase in melting point with draw ratio was con-
Table III. Changes in crystallinity and melting point of heat-treated samples as a function of the draw ratio

\begin{tabular}{cccc}
\hline $\begin{array}{c}\text { Anneling } \\
\text { temperature }\end{array}$ & $\begin{array}{c}\text { Draw } \\
\text { ratio/ } \lambda\end{array}$ & $\begin{array}{c}\text { Crystal- } \\
\text { linity } / \%\end{array}$ & $\begin{array}{c}\text { Melting } \\
\text { point } /{ }^{\circ} \mathrm{C}\end{array}$ \\
\hline & 5 & 83.0 & 138 \\
$80^{\circ} \mathrm{C}$ & 10 & 84.0 & 139 \\
& 15 & 84.0 & 139 \\
& 20 & 85.5 & 141 \\
\hline $100^{\circ} \mathrm{C}$ & 5 & 83.5 & 139 \\
& 10 & 84.0 & 140 \\
& 15 & 84.5 & 142 \\
& 20 & 85.5 & 142 \\
\hline $120^{\circ} \mathrm{C}$ & 5 & 83.0 & 140 \\
& 10 & 84.0 & 140 \\
& 15 & 85.5 & 141 \\
& 20 & 86.0 & 141 \\
\hline
\end{tabular}

firmed for the specimens but melting points were hardly affected by annealing temperature. It may be noted that the crystallinities of all the gel films with $\lambda=20$ are higher than $85 \%$. The gel films with such high crystallinities could not be prepared by the elongation of melt press films molten by the present LMWPE. The crystallinities were confirmed to be higher than those for the drawn melt films. That is, the crystallinity of melt film drawn to $\lambda=10$ at $135^{\circ} \mathrm{C}$ increased only from $61(\lambda=1)$ to $75 \%(\lambda=10)$.

Figure 3 shows variation in birefringence with the draw ratio $\lambda$. At an initial draw ratio less than 4 , macroscopic observation revealed that the drawing process is slightly nonuniform and the drawn film consists of two alternating zones: unoriented area and oriented area. As the draw ratio increased, the oriented zones were enlarged at the expense of the unoriented zone. When fractures occurred after stretching, it was invariably at the boundary between the two zones. Decrease in transverse dimensions with increasing draw ratio occurred mainly in the direction of the film thickness and much less in the film width. 


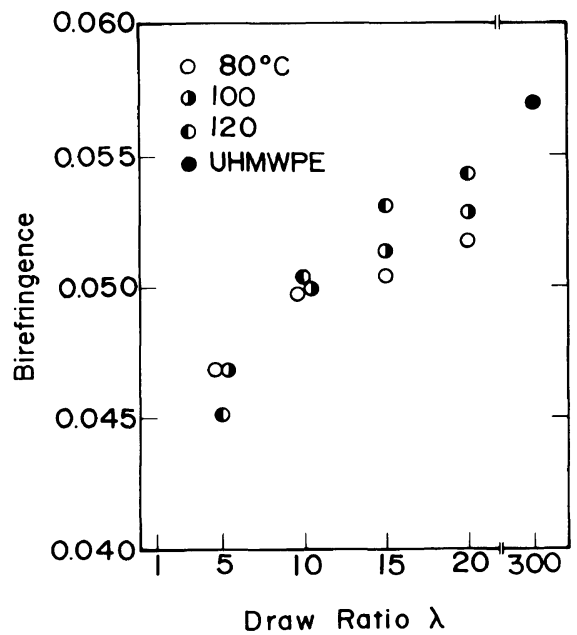

Figure 3. Birefringence of gel films prepared by heating at the indicated temperatures under compression of $20 \mathrm{MPa}$ and UHMWPE gel films as a function of draw ratio.

Beyond $\lambda=5$, deformation became uniform macroscopically. Thus it may be expected that crystal transformation from a folded to a fibrous type occurs at $\lambda \leqq 4$. However, this phenomenon is not significant in comparison with the deformation mechanism of UHMWPE gel films. The necking deformation described above hampered measurement of birefringence for specimens with $\lambda \leqq 4$. Birefringence for all specimens showed a considerable increase up to $\lambda=5$ and a gradual increase beyond $\lambda=5$, indicating significant crystal transformation at initial elongation stage $(\lambda \leqq 4)$.

Figure 4 shows the second-order orientation factor, $F_{\mathrm{c}}$, of the $c$-axes. The factor $F_{\mathrm{c}}$ characterizes the orientation of crystal fiber axes with variation between $-1 / 2$ and 1 . For random orientation of the $j$-th axis, $F_{\mathrm{c}}$ is zero, while for complete orientation parallel and perpendicular to the stretching direction, $F_{20}{ }^{j}$ is unity and $-1 / 2$, respectively. Estimation was by direct measurement for the $\left(\begin{array}{lll}0 & 0 & 2\end{array}\right)$ plane.

As can be seen in Figure 4, for all specimens, the $c$-axes are oriented almost perfectly

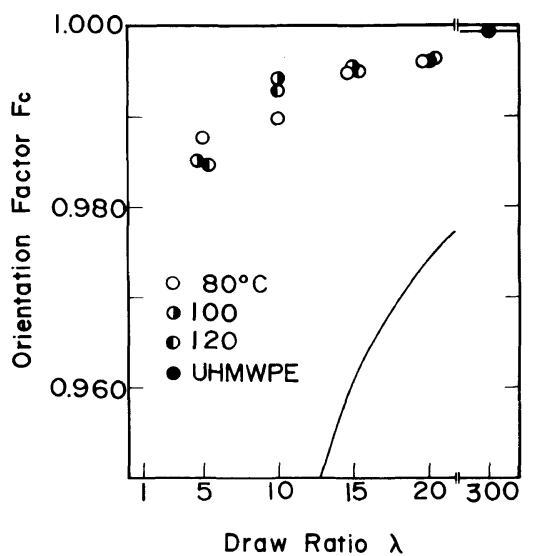

Figure 4 Second-order orientation factor of the $c$-axes of gel films prepared by heating at the indicated temperatures under compression of $20 \mathrm{MPa}$ and UHMWPE gel films as a function of draw ratio. The line is the value calculated by an affine fashion.

with respect to the stretching direction even at an initial draw ratio such as $\lambda=5$. Such a drastic preferential orientation is due to a significant crystal transformation from a folded to a fibrous type in the initial stage of elongation. The full curve in Figure 4 is the second-order orientation factor calculated assuming an affine fashion. The calculated curve is in poor agreement with the experimental results. According to the report by Smith et al., ${ }^{4}$ however, the Young's modulus of polyethylene at various draw ratio was estimated using a series model which consist of perfectly oriented and unoriented phases through the fraction of helix corresponding to the second-order orientation factor calculated assuming the affine fashion. Apart from the results by Smith et al., ${ }^{4}$ however, the orientation of $c$-axes of polyethylene film is independent of the affine fashion for the present specimens.

Table IV shows the average Young's modulus and tensile strength of the LMWPE gel films prepared by heating at a pressure of $20 \mathrm{MPa}$. The Young's modulus and tensile strength are almost independent of the heattreated effect and the values are in the range 
Table IV. Young's modulus and tensile strength of heat-treated gel films at $\lambda=20$

\begin{tabular}{ccc}
\hline $\begin{array}{c}\text { Annealing } \\
\text { temperature }\end{array}$ & $\begin{array}{c}\text { Young's } \\
\text { modulus/GPa }\end{array}$ & $\begin{array}{c}\text { Tensile } \\
\text { strength/GPa }\end{array}$ \\
\hline $80^{\circ} \mathrm{C}$ & 32.4 & 1.10 \\
$100^{\circ} \mathrm{C}$ & 33.9 & 1.17 \\
$120^{\circ} \mathrm{C}$ & 32.5 & 1.06 \\
\hline
\end{tabular}

of $32-34$ and $1.1-1.2 \mathrm{GPa}$, respectively. In spite of almost perfect orientation of the $c$ axes as shown in Figure 4, both values are much lower than those of UHMWPE gel films. That is, the Young's modulus and tensile strength of drawn UHMWPE gel film with $\lambda=300$ are beyond 200 and $6 \mathrm{GPa}$, respectively. ${ }^{5,6}$ The question arises as to why both values of LMWPE gel film are much lower than those of UHMWPE gel film in spite of the almost perfect orientation of the $c$-axes at maximum draw ratios as shown in Figure 4. In a previous work, we reported that this should be accompanied by low crystallinity and short length of extended chain crystals ${ }^{7}$ since these factors prevent the formation of uniform structures within drawn films which play important roles to transmit tensile force smoothly.

Next, a series of experimental results of LMWPE gel films prepared by partial melt were compared with morphology and mechanical properties of UHMWPE melt films. WAXD and SAXS patterns indicate random orientations of crystal lamellae and crystallites within UHMWPE melt films. Figure 5 shows the second-order orientation factors of UHMWPE melt films with $\bar{M}_{v}=1 \times 10^{6}$ and $3 \times 10^{6}$. The specimens were drawn at the indicated temperatures. Prior to the drawing, the specimens were annealed for $10 \mathrm{~min}$ at the same temperature. $125^{\circ} \mathrm{C}$ was the lowest temperature to assure elongation without necking. $140^{\circ} \mathrm{C}$ was not suitable for the specimen with $\bar{M}_{v}=1 \times 10^{6}$ because of partial melting of the specimen prior to elongation and the upper limit for the specimen was set

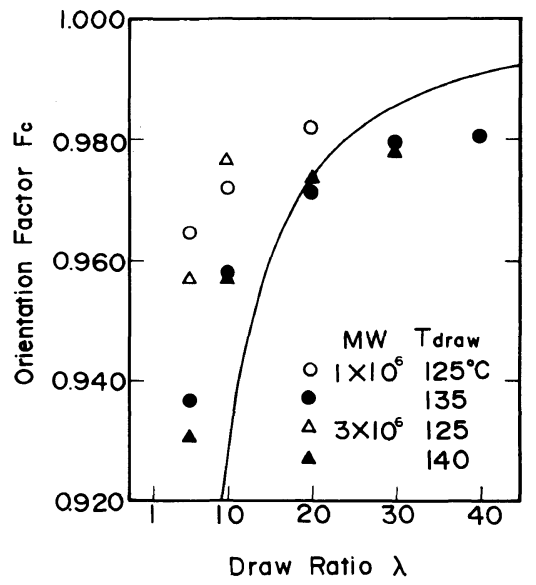

Figure 5 Second-order orientation factor of the $c$-axes of the UHMWPE melt films drawn to their maximum draw ratios at the indicated temperatures. The line is the value calculated by an affine fashion.

at $135^{\circ} \mathrm{C}$. Actually, DSC measurements (not shown in this paper) indicated a main peak for the specimen drawn by 40 times at $135^{\circ} \mathrm{C}$ appeared at $133^{\circ} \mathrm{C}$ and a very small new peak made by elongation was $152^{\circ} \mathrm{C}$.

As shown in Figure 5, the maximum draw ratio was sensitive to elongation temperature and molecular weight. For the specimens with the same molecular weight, in the given temperature range $125-140^{\circ} \mathrm{C}$, the orientation factor at each draw ratio became less pronounced with increasing elongation temperature. In contrast, the drawability became more pronounced with temperature. The drawing perhaps resulted from slippage of molecular chains in the specimen. Even so, the maximum value of all the specimens became about 0.98 indicating highly orientational degree. The orientation factor calculated by assuming an affine fashion (full curve) is in poor agreement with the experimental results. The results in Figures 4 and 5 indicate that the crystal orientation of our specimens deviates from an affine fashion and are out of the concept of Irvine and Smith. ${ }^{4}$

The crystallinity at the maximum draw ratio for each specimen is more pronounced 


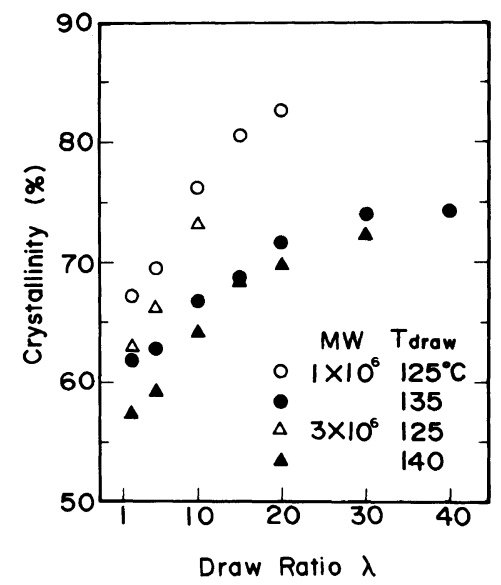

Figure 6 Change in crystallinity of the UHMWPE melt films drawn to their maximum draw ratios at the indicated temperatures.

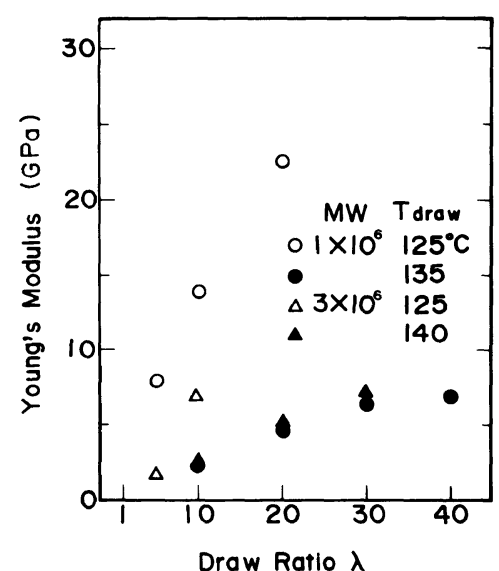

Figure 7 Change in Young's modulus of the UHMWPE melt films drawn to their maximum draw ratios at the indicated temperatures.

irrespective of draw ratio, as their elongation temperatures decrease as shown in Figure 6. This indicates slippage of molecular chains during elongation, as discussed in Figure 5. The maximum value of crystallinity was achieved when the specimen $\left(\bar{M}_{v}=1 \times 10^{6}\right)$ was elongated at $125^{\circ} \mathrm{C}$. By this condition, the value reached $83 \%$. The increase in crystallinity is probably due to oriented crystallization associated with the inner stress.

Figure 7 shows Young's modulus versus draw ratio $\lambda$, obtained for specimens drawn at each elongation condition. The increasing Young's modulus is in good agreement with increase in orientation factor and crystallinity at each draw ratio. It is seen that the Young's modulus, $23 \mathrm{GPa}$, of the melt film with $\bar{M}_{v}=$ $1 \times 10^{6}$ drawn at $125^{\circ} \mathrm{C}$ is highest among the melt drawn films and the corresponding values of orientation factor and crystallinity are also highest. The maximum value at $\lambda=20$, however, is at best $23 \mathrm{GPa}$, which is less than the value of LMWPE gel films listed in Table IV. This is probably due to the lower values of crystallinity and orientation factor obtained for the UHMWPE melt films than those for the LMWPE gel films described before. (See Table III and Figure 4.) This means that a number of entanglements for melt films having spherulites hampers significant crystal transformation from a folded to fibrous type and orientation of the $c$-axes is attributed to the rotation of crystallites leading to taut tie molecules. ${ }^{8}$

For UHMWPE melt film, long periods would be observed by SAXS patterns and values for all the specimens were less than $300 \AA$. That is, the long periods for the specimens $\left(\bar{M}_{v}=1 \times 10^{6}\right)$ drawn 40 times at $135^{\circ} \mathrm{C}$ and 20 times at $125^{\circ} \mathrm{C}$ were in the range $280-300 \AA$. In contrast, a long period has never been observed for UHMWPE gel film drawn beyond $\lambda=50 .^{7}$ This supports that crystallites within the drawn UHMWPE melt films are the folded type as discussed before. The long period of the LMWPE gel film becomes indistinct because of shift of the scattering maximum to the scattering center. Unfortunately, measurements by our X-ray instrument were impossible, since the length of optical bench was less than $400 \mathrm{~mm}$. This supports significant crystal transformation of the LMWPE gel films from a folded to a fibrous type.

Even the maximum Young's modulus obtained for the UHMWPE $\left(\bar{M}_{v}=1 \times 10^{6}\right)$ at $125^{\circ} \mathrm{C}$ was $23 \mathrm{GPa}$. This supports the results 
of Porter et al..$^{9-11}$ and Ward et al. ${ }^{12-14}$ In their experiments, the production of highmodulus fibers were done using LMWPE with $\bar{M}_{v}<10^{5}$ using hydrostatic extrusion. The Young's modulus reached about $70 \mathrm{GPa}$, which is much higher than the maximum value $(23 \mathrm{GPa})$ of the Young's modulus of UHMWPE $\left(\bar{M}_{v}=1 \times 10^{6}\right)$ melt film. According to reports by Ward et al., low molecular weight $\left(\bar{M}_{v}<10^{5}\right)$ was a very important factor to promote the maximum draw ratio. They pointed out that this is attributed to reduction in intermolecular tie molecules in the undrawn state with decreasing $\bar{M}_{v}$. Porter $e t$ al. pointed out that the Young's modulus versus draw ratio of extruded high density polyethylene depends on the extrusion temperature related to $c$-axis orientation, non-crystalline orientation factor, crystallinity, and the composite mode of crystal and amorphous phases.

\section{CONCLUSIONS}

Half-dried LMWPE gels were pressed at temperatures $80-120^{\circ} \mathrm{C}$ to form a film. SAXS patterns indicate that the resultant gel film is composed of crystal lamellae highly oriented with their large flat faces parallel to the film surface. The significant crystal transformation from a folded to a fibrous type occurred at initial draw ratio $\lambda<4$ and at $\lambda=5$ the $c$-axes were oriented almost perfectly with respect to the stretching direction. This indicates that in comparison with LMWPE and UHMWPE melt films used in this experiment, the partial melt due to the heat-treatment assures a more suitable number of entanglements which play important roles to transmit drawing force effectively within the film. The identity period of LMWPE gel films at $\lambda=20$ was longer than that $(300 \AA)$ of drawn UHMWPE melt film. The Young's modulus of the film was higher than $30 \mathrm{GPa}$ and this value was higher than the maximum value $(23 \mathrm{GPa})$ of UHMWPE melt film drawn up to 30 times. The Young's modulus of the LMWPE gel film drawn by 20 times. However, this is much lower than that of UHMWPE gel film drawn to 300 . This is due to lower crystallinity and shorter extended crystallites of the former film in comparison with the latter film. Because of chain short length, these essential defects are thought due to a predestined problem of LMWPE.

\section{REFERENCES}

1. C. Sawatari, T. Okumura, and M. Matsuo, Polym. J., 18, 741 (1986).

2. C. Sawatari, S. Shimogiri, and M. Matsuo, Macromolecules, 20, 1033 (1987).

3. W. O. Statton and P. H. Geil, J. Appl. Polym. Sci., 3, 357 (1960).

4. P. A. Irvine and P. Smith, Macromolecules, 19, 240 (1986).

5. M. Matsuo, K. Inowe, and N. Abumiya, Sen- $i$ Gakkaishi, 40, 275 (1984).

6. C. Sawatari and M. Matsuo, Colloid Polym. Sci., 263, 783 (1985)

7. C. Sawatari and M. Matsuo, Polymer, 30, 1603 (1989).

8. M. Matsuo, K. Hirota, K. Fujita, and H. Kawai, Macromolecules, 11, 1000 (1978).

9. S. Kojima and R. S. Porter, J. Polym. Sci., Polym. Phys. Ed., 16, 1729 (1978).

10. W. T. Mead, C. R. Porter, and R. S. Porter, J. Polym. Sci., Polym. Phys. Ed., 17, 859 (1979).

11. M. Ito, T. Kanamoto, K. Tanaka, and R. S. Porter, Macromolecules, 14, 1779 (1979).

12. J. M. Andrews and I. M. Ward, J. Mater. Sci., 5, 411 (1970).

13. J. Clements, G. Capaccio, and I. M. Ward, J. Polym. Sci., Polym. Phys. Ed., 17, 693 (1979).

14. J. Clements, R. Jakeways, and I. M. Ward, Polymer, 19, 639 (1978). 